\title{
Erratum to: Distributed Computing and Artificial Intelligence, 13th International Conference
}

Sigeru Omatu, Ali Selamat, Grzegorz Bocewicz, Pawel Sitek, Izabela Nielsen, Julián A. García-García and Javier Bajo

\section{Erratum to:}

S. Omatu et al. (eds.),

Distributed Computing and Artificial Intelligence, 13th International Conference, Advances in Intelligent Systems and Computing, DOI: 10.1007/978-3-319-40162-1

In the original version, the volume editor's name was misspelled in the copyright page. The correct name is Ali Selamat. 